hoàn toàn chính xác kết quả của can thiệp tầng ĐM chậu. Sự ảnh hưởng huyết động học do tổn thương tầng dưới ĐM chậu tạo nên sự rối loạn dòng chảy tầng ĐM chậu, về lẩu dài dẫn đến hẹp hoặc tắc nghẽn tầng ĐM chậu.

Hơn nữa, trong giai đoạn trung hạn, các yếu khác cũng góp phần làm kết quả trung hạn xấu đi như rối loạn mõ̃ máu, hút thuốc lá, đái tháo đường [9]. Trong nghiên cứu chúng tôi, bệnh nhân được kiểm tra siêu âm, đo $A B I$, có thể phối hợp chụp CTA khi tái khám mỗi tháng. Tất cả cũ̉ng nhằm đánh giá mức độ tái thông tầng ĐM chậu sau can thiệp cũng như tưới máu tầng dưới ĐM chậu kèm theo. Bên cạnh đó, bệnh nhân cũng được xét nghiệm máu, siêu âm tim, siêu âm mạch máu cảnh khi cần thiết để đánh giá các yếu tố nguy cơ và bệnh phối hợp của bệnh nhân. Toa thuốc chúng tổi luôn có thuốc điều trị tắc động mạch, thuốc kháng tiểu cầu, có thể kèm mõ̃ máu và thuốc chống loét dạ dày. Nếu có các bệnh lý về tim, về nội tiết hoặc các chuyên khoa khác chúng tôi luôn cho bệnh nhận đi khám chuyên khoa và dặn bệnh nhần uống thuốc phối hợp giữa các chuyên khoa chu đáo.

\section{KẾT LUẬN}

Phương pháp đặt giá đỡ nội mạch đơn thuần đã thành công khi tái tưới máu chi dưới đạt kết quả cao, với tỷ lệ thành công về kỷ thuật và trung hạn chiếm lần lượt 96,6\% và 90,1\% mẫu nghiên cứu. Kết quả bước đầu đem lại khả quan về hướng can thiệp đơn thuần bằng phương pháp đặt giá đõ̃ nội mạch với những tổn thương chủ yếu là TASC II $A, B$.

\section{TÀI LIÊU THAM KHẢO}

1. Taylor M Spence, John W. York (2010), "Lower Extremity Arterial Disease: Decision Making and Medical Treatment", Rutherford's Vascular Surgery, 7 ed., 2, Chap 104, pp.1593 - 1612.

2. Nguyển Lân Việt, Phạm Việt Tuân, Phạm Manh Hùng (2010), "Nghiên cứu mô hình bểnh tât ở bệnh nhân điêu trị nội trú tại Viện Tim mạch Việt nam trong thời gian 2003-2007". Tạp chí Tim mạch học Việt Nam, số 52, tr. 11-17.

3. Rutherford RB, Baker JD, Ernst C, Johnston KW, Porter JM, Ahn S, Jones DN (1997), "Recommended standards for reports dealing with lower extremity ischemia: revised version". J Vasc Surg, 26, pp.517-538.

4. Hirsch AT C. M., Treat-Jacobson D, Regensteiner J, Creager $M$, Olin J, et al. (2001), "The PARTNERS program: A national survey of peripheral arterial disease detection, awareness, and treatmen ", Vol 286(11), pp.1317-1324.

5. Jakobs TF W. B., Becker CR (2004), "MDCTimaging of peripheral arterial disease", Semin Ultrasound CT MR 2004, Vol 25(2), pp.145-155.

6. Klein WM, van der Graaf $Y$, Seegers J, Spithoven 'JH, Buskens E, van Baal JG, Buth' J, Moll FL, Overtoom TT, van Sambeek MR, Mali WP (2006), "Dutch Iliac Stent Trial: longterm results in patients randomized for primary or selective stent placement", Radiology, 238: 734-744.

7. AbuRahma AF, Hayes JD, Flaherty SK, Peery W. (2007), "Primary iliac stenting versus transluminal angioplasty with selective stenting". J Vasc Surg. ;46(5):pp.965-970.

8. Norgren $L$, Hiatt WR, Dormandy JA, et al. (2007), "TASC II, Working Group. Inter-society Consensus for the Management of Peripheral Arterial Disease (TASC II)". Eur J Vasc Endovasc Surg; 33 Suppl 1: S1-75.

9. Kudo T, Chandra FA, Ahn SS (2005) "Long-term outcomes and predictors of iliac angioplasty with selective stenting", J Vasc Surg, 42(3): pp.466-75.

\title{
THẤU HIỂU BẢN THÂN Ở NGƯờI BÊNNH TÂM THẦN PHÂN LIỆT THỂ PARANOID
}

\section{Trần Thị Thu Hà*, Nguyễn Văn Tuấn*, Nguyễn Hoàng Yến*, Đoàn Thị Huệ*, Nguyễn Mạnh Hùng*}

\section{TÓM TẮT}

Thấu hiểu bản thân là một trong những triệu chứng phổ biến của tâm thần phân liệt. Thấu hiểu bản thân là một khái niệm đa chiều phức tạp, gồm có khả năng nhận thức về bản chất của bệnh, các triệu chứng của bệnh, nguồn gốc của bệnh, sự cân thiết điều trị và

*Trường Đại học Y Hà Nội

Chịu trách nhiệm chính: Trần Thị Thu Hà

Email: Tran_thuha@hmu.edu.vn

Ngày nhận bài: 9.7.2021

Ngày phản biên khoa học: 3.9.2021

Ngày duyệt băi: 10.9.2021 các hậu quả xã hội của chúng. Hiện nay ở Việt Nam chưa có nghiên cứu về vấn đề này, do đó chúng tôi thực hiện nghiên cứu "đăc điểm lâm sàng thấu hiểu bản thẩn ở người bệnh tâm thần phân liệt thể Paranoid" với mục tiêu: "Mô tả đăc điểm lâm sàng thấu hiểu bản thân ở bệnh nhân tầm thần phân liệt thể Paranoid". Đối tượng và phương pháp nghiên cứu: Nghiên cứu mô tả cắt ngang 69 người bệnh tâm thần phân liệt thể Paranoid điêu trị nội trú tại Viện sức khỏe Tâm thần, Bệnh viện Bạch Mai từ tháng 8/2020 4/2021. Kết quả: Đối tượng nghiên cứu là nữ chiếm $52,2 \%$, tuổi trung bình $31,81 \pm 11,877$. Điểm thấu hiểu bản thân trên thang SAI-E là 13,25 $\pm 5,779$, điểm ba thành phần thấu hiểu bản thân: thấu hiêu rối loạn tâm 
thần (SAI-EF1) 5,17 \pm 2,985, thấu hiểu nguồn gốc triêu chứng tâm thần (SAI-EF2) là $7,38 \pm 3,710$, thấu hiểu nhu câu điều trị (SAI-EF3) là 13,25 $\pm 5,779$. Không ghi nhận mối tương quan giữa triệu chứng dương tính và thấu hiểu bản thân. Mối tương quan nghịch giữa điểm thấu hiểu bản thân thang SAI-E với triệu chứng âm tính, triệu chứng tâm bệnh học chung với $p<0,05$.

\section{SUMMARY \\ INSIGHT IN PARANOID SCHIZOPHRENIA}

Insight is one of the most common phenomenon among patients with schizophrenia. Insight is a complex multidimensional concept that includes awareness of mental disorder, understanding of the social consequences of disorder, awareness of the need for treatment, awareness of specific signs and symptoms of disorder and the attribution of symptoms to disorder. There are many studies on insight in schizophrenia in the world, but there is no research on this issue in Vietnam. Therefore, we carried out a study on "clinical characteristics of insight among patients with paranoid schizophrenia" with the aim: "Describe clinical characteristics of insight among patients with Paranoid schizophrenia". Subjects and methods: A cross-sectional descriptive study of 69 patients with Paranoid schizophrenia undergoing inpatient treatment at the Mental Health Institute, Bach Mai Hospital from August 2020 to April 2021. Results: Female subjects accounted for $52.2 \%$, the average age was $31.81 \pm 11,877$. insight score on the SAI-E scale is $13.25 \pm 5.779$, the three-component of insight score SAI-EF1 (awareness of mental disorder) $5.17 \pm 2.985$, SAI-EF2 (the attribution of symptoms to disorder) is $7.38 \pm 3,710$, SAI-EF3 (awareness of the need for treatment) is $13.25 \pm 5.779$. No correlation between insight and positive symptoms was recorded. Negative correlation between insight with negative symptoms, general psychopathological symptoms with $\mathrm{p}<0.05$.

\section{I. ĐĂT VẤN ĐỀ}

Tâm thần phân liệt là một rối loạn tâm thần nghiêm trọng, khá phổ biến ở các nước trên thế giới với tỷ lệ khoảng $0,3-0,5 \%$ dân số. Thấu hiểu bản thân là một khái niệm có quan hệ mật thiết với các bệnh lý tâm thần và được công nhận là một khái niệm đa chiều phức tạp, gồm có khả năng nhận thức về bản chất của bệnh, các triệu chứng của bệnh, nguồn gốc của bệnh, sự cần thiết điều trị và các hậu quả xã hội của chúng ${ }^{1}$. Theo Lincoln 2006, 30-50\% bệnh nhân tâm thần phân liệt thiếu sự thấu hiểu bản thân, đồng nghĩa với việc họ không thể hiểu được bệnh lý của họ cũng như sự cần thiết điều trị ${ }^{2}$. Thiếu sự thấu hiểu bản thân được tin rằng góp phần ảnh hưởng đến việc bất tuân trị, tăng nguy cơ tái phát, tăng khả năng nhập viện, suy giảm chức năng tâm thần Hiện nay chưa có nghiên cứu về thấu hiểu bản thân ở bệnh nhân tâm thần phân liệt tại Việt Nam. Vì vậy, để góp phần làm rõ đặc điểm của thấu hiểu bản thân ở bệnh nhân tâm thần phân liệt tại Việt Nam, chúng tôi tiến hành thực hiện nghiên cứu đề tài: "Nghiên cứu đặc điểm lầm sàng thấu hiểu bản thân ở bệnh nhân tâm thần phân liệt thể Paranoid".

\section{II. ĐỐI TƯợNG VÀ PHƯƠNG PHÁP NGHIÊN CỨU} Đối tượng, địa điểm, thời gian nghiên cứu: 69 bệnh nhân được chẩn đoán là TTPL thể Paranoid theo bảng phân loại hệ thống bệnh quốc tế lần thứ 10 (ICD 10) của Tổ chức Y tế thế giới. Các bệnh nhân tâm thần phân liệt điều trị nội trú tại Viện sức khỏe Tâm thần, bệnh viện Bạch Mai

Tiêu chuẩn lựa chọn: Bệnh nhân đồng ý tham gia vào nghiển cứu.

Tiêu chuấn loại trừ: Bệnh nhân có các biến chứng mạn tính nặng hoặc các bệnh cơ thể nặng kèm theo làm hạn chế khả năng giao tiếp của người bệnh

Phương pháp nghiên cứu: Phương pháp mô tả cắt ngang, Cỡ mẫu được tính theo công thức ước tính tỷ lệ trong một quần thể

Phân tích, xử lí số liệu: Các số liệu được phân tích và xử lý bằng phần mềm SPSS 20.0

\section{KẾT QUẢ NGHIÊN CỨU}

3.1. Đặc điểm nhân khẩu học và triệu chứng tâm thần phân liệt nhóm nghiên cứu Bảng 1: Đặc điểm nhân khẩu xã hội

\begin{tabular}{|c|c|c|c|}
\hline \multicolumn{2}{|c|}{ Đặc điểm } & $\begin{array}{c}\text { Số lượng } \\
\text { (n) }\end{array}$ & $\begin{array}{l}\text { Tỷ lệ } \\
(\%)\end{array}$ \\
\hline \multicolumn{2}{|c|}{ Tuối trung bình $(\bar{x} \pm S D)$} & \multicolumn{2}{|c|}{$31,81 \pm 11,877$} \\
\hline \multirow{2}{*}{ Giới } & Nữ & 36 & 52,2 \\
\hline & Nam & 33 & 47,8 \\
\hline \multirow{4}{*}{$\begin{array}{l}\text { Trình độ } \\
\text { học vấn }\end{array}$} & $\begin{array}{l}\text { Tiểu học trở } \\
\text { xuống }\end{array}$ & 8 & 11,6 \\
\hline & THCS & 19 & 27,5 \\
\hline & THPT & 22 & 31,9 \\
\hline & $\begin{array}{c}\text { Đại học và sau } \\
\text { đại học }\end{array}$ & 20 & 29,0 \\
\hline \multirow{2}{*}{ Nơi cư trú } & $\begin{array}{l}\text { Nông thôn, miền } \\
\text { núi }\end{array}$ & 50 & 65,2 \\
\hline & Thành phố & 24 & 34,8 \\
\hline \multicolumn{2}{|c|}{$\begin{array}{c}\text { Tuối khởi phát trung bình } \\
(X \pm S D)\end{array}$} & \multicolumn{2}{|c|}{$23,84 \pm 8,879$} \\
\hline \multicolumn{2}{|c|}{$\begin{array}{l}\text { Thời gian mắc bệnh trung } \\
\text { bình }(x \pm S D)\end{array}$} & \multicolumn{2}{|c|}{$78,04 \pm 86,123$} \\
\hline
\end{tabular}

Nhân xét: Tuối trung bình của nhóm đối tượng nghiên cứu là $31,81 \pm 11,877$. Nghiên cứu có $52,2 \%$ bệnh nhân là nữ, $47,8 \%$ là nam giới. Về trình độ học vấn, trình độ tiểu học trở xuống chiếm tỉ lệ thấp nhất $(11,6 \%)$, trung học phổ thông cao nhất 31,9\%. Trong nghiên cứu có 
34,8\% bệnh nhân TTPL sống ở thành thị, 65,2\% bệnh nhần sống tại nông thôn, miền núi. Nghiên cứu báo cáo tuổi khởi phát trung bình là 23,84 \pm 8,879 . Thời gian mắc bệnh trung bình là $78,04 \pm 86,123$ tháng (khoảng 6,4 năm).

Bảng 2: Đặc điềm triệu chứng tâm thần phân liệt trên thang PANSS

\begin{tabular}{|c|c|c|}
\hline \multicolumn{2}{|c|}{ Thang điểm } & $\begin{array}{c}\text { Trung bình } \\
(\bar{x} \pm \mathrm{SD})\end{array}$ \\
\hline PANSS-P & PANSS dương tính & $21,77 \pm 7,733$ \\
\hline PANSS-N & PANSS âm tính & $19,33 \pm 8,721$ \\
\hline PANSS-G & $\begin{array}{c}\text { PANSS tâm bệnh } \\
\text { học chung }\end{array}$ & $38,58 \pm 9,569$ \\
\hline
\end{tabular}

Nhận xét: Nghiên cứu của chúng tôi cho thấy điểm số 3 nhóm nhỏ của thang PANSS (PANSS dương tính, PANSS âm tính và PANSS tâm bệnh học chung) có điểm trung bình tương ứng là $21,77 \pm 7,733 ; 19,33 \pm 8,721 ; 38,58 \pm 9,569$

3.2. Đăcc điểm thấu hiểu bản thân nhóm nghiên cứu

Bảng 3: Đặc điểm thấu hiểu bản thân trên thang SAI-E

\begin{tabular}{|c|c|}
\hline Triệu chứng & $\bar{\chi} \pm \mathrm{SD}$ \\
\hline Thấu hiểu về rối loạn tâm thần & $5,17 \pm$ \\
(SAI-EF1) & 2,985 \\
\hline Thấu hiểu về nguồn gốc rối & $7,38 \pm$ \\
loạn tâm thần (SAI-EF2) & 3,710 \\
\hline Thấu hiểu nhu cầu điều trị & $2,26 \pm$ \\
(SAI-EF3) & 1,763 \\
\hline Thấu hiểu bản thân chung & $13,25 \pm$ \\
(SAI-E) & 5,779 \\
\hline
\end{tabular}

Nhận xét: nghiên cứu của chúng tôi báo cáo điểm trung bình thang SAI-E về ba khía cạnh của thấu hiểu bản thân: thấu hiểu về dấu hiệu và triệu chứng tâm thần là $5,17 \pm 2,985$, thấu hiểu về nguồn gốc rối loạn tâm thần là $7,38 \pm 3,710$, thấu hiểu nhu cầu điều trị $2,26 \pm 1,763$ và tổng điểm trung bình của thang SAI-E 13,25 $\pm 5,779$

Bảng 4: Tương quan điểm trung bình thang SAI-E với triệu chứng dương tính, âm tính, tâm bệnh học chung trên thang PANSS

\begin{tabular}{|c|c|c|}
\hline & $\begin{array}{c}\text { Điếm số SAI-E } \\
\text { Hệ số tương quan }\end{array}$ & p \\
\hline PANSS P & $-0,181$ & 0,136 \\
\hline PANSS N & $-0,238$ & 0,049 \\
\hline PANSS G & $-0,387$ & 0,001 \\
\hline
\end{tabular}

Nhận xét: Nghiên cứu cho thấy không có mối tương quan giữa điểm thấu hiểu bản thân chung SAI-E với triệu chứng dương tính, nhưng có mối tương quan nghịch với triệu chứng âm tính $(r=-0,238)$ và triệu chứng tâm bệnh học chung $(r=-0,387)$ với $p<0,05$.

\section{BÀN LUÂN}

4.1. Đặc điểm nhân khẩu học và triệu chứng tẩm thần phân liệt nhóm nghiển cứu. Độ tuổi trung bình của bệnh nhân là $31,81+11,877$, Kết quả của chúng tôi tương đồng với nghiên cứu của Kim về thấu hiểu bản thân ở bệnh nhân tâm thần phân liệt: $35.0 \pm$ $8.2^{3}$. Tỷ lệ nữ /nam là $1,09 / 1$. 31,9\% có trình độ trung học phổ thông chiểm tỳ lệ cao nhất. $65,2 \%$ bệnh nhân sống tại nông thôn, miền núi. Tuổi khởi phát bệnh trung bình trong nghiên cứu của chúng tôi là $23,83 \pm 8,879$, tương đồng với Mintz: $23,9 \pm 5,4^{4}$. Thời gian mắc bệnh trung

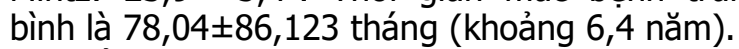

Điểm trung binh thang PANSS dương tính là $21,77 \pm 7,733$ và thang PANSS âm tính là 19,33 $\pm 8,721$, thang PANSS tâm bệnh học chung là $38,58 \pm 9,569$. Kết quả này tương ứng với các nghiên cứu trước đây: Tariku nghiên cứu 445 người bệnh tâm thần phân liệt có điểm trung bình thang PANSS dương tính là $22,67 \pm 6,12$, điểm trung bình thang PANSS âm tính là 22,36 $\pm 3,69$, thang tâm bệnh học chung là $27,42 \pm 10,45^{5}$.

4.2. Đặc điểm thấu hiểu bản thân nhóm nghiên cứu.

Đặc điểm thấu hiểu bản thân trên thang SAI-E. Trong nghiên cứu điểm trung bình thang SAI-E là $13,25 \pm 5,779$, ba khía cạnh của thấu hiểu bản thân: thấu hiểu về triệu chứng tâm thần $5,17 \pm 2,985$, thấu hiểu về nguồn gốc rối loạn tâm thần $7,38 \pm 3,710$, thấu hiểu nhu cầu điều trị $2,26 \pm 1,763$. Lisette van der Meer có điểm trung bình SAI-E là $13,0 \pm 5,7$, ba khía cạnh thấu hiểu bản thân tương ứng là $8,2 \pm 3,5$; $3,3, \pm 2,0$ và $1,5 \pm 1,5^{6}$.

Mối liên quan giữa thấu hiểu bản thân SAI-E với triệu chứng tâm thân phân liệt trên thang PANSS. Nghiên cứu không chỉ ra mối tương quan giữa thấu hiểu bản thân trên thang SAI-E với triệu chứng dương tính theo thang PANSS với $p=0,136$. Kết quả của chúng tôi khác biệt so với một số nghiên cứu khác: Mintz tiến hành nghiên cứu gộp 22 nghiên cứu với 1616 người bệnh tâm thần phân liệt cho thây mối tương quan nghịch: triệu chứng dương tính càng tăng thì thấu hiểu bản thân càng giảm với $p<0,001^{4}$. Sự khác biệt này có thể giải thích liên quan đến quá trình chọn mấu, lựa chọn công cụ nghiên cứu, mức độ nghiêm trọng của triệu chứng khác nhau.

Chúng tôi ghi nhận mối tương quan nghịch giữa các triệu chứng âm tính của tâm thần phân liệt theo thang PANSS với sự thấu hiểu bản thân qua thang SAI- E với $r=-0,238, p<0,05$. Điều 
này nghĩa là các triệu chứng âm tính càng nhiều, mức độ càng nặng thì sự thấu hiểu bản thân càng ít và kém. Ngay từ năm 1998, tác giả Cuesta và các cộng sự nghiên cứu cũng cho thẫy kết quả tương tự như của chúng tôi.

Nghiên cứu nhận thấy có mối liên quan nghịch giữa sự thấu hiểu bản thân trên thang SAI-E và mức độ nặng của các triệu chứng tâm bệnh học chung PANSS $G(p<0,05)$. Kết quả này phù hợp với đa số các nghiên cứu trên thế giới, như tác giả Pierre và CS năm 2013 đã nghiên cứu trên 531 bệnh nhân thấy rằng sự thấu hiểu và triệu chứng tâm bệnh học có liên quan mật thiết với nhau với $\mathrm{p}<0,01$. Ông đề xuất suy giảm khả năng thấu hiểu được xem như một giá trị tiên đoán cho các kết quả và đáp ứng điều trị kém ở bênh nhân tâm thần phân liêt, bởi vì kém thấu hiểu bản thân ảnh hưởng đến chất lượng cuộc sống của bệnh nhân và làm tăng nguy cơ tái phát và tái nhập viện?

\section{KẾT LUẬN}

Thấu hiểu bản thân là triệu chứng thường gặp trong bệnh cảnh tâm thần phân liệt thể Paranoid. Điểm số chung trên thang đánh giá thấu hiểu bản thân SAI-E là 13,25 $\pm 5,779$. Thấu hiểu bản thân không có mối liên quan với triệu chứng dương tính, tuy nhiên có mối liên quan nghịch với triệu chứng âm tính và tâm bệnh học chung trên thang PANSS.

\section{TÀI LIÊU THAM KHẢO}

1. Anthony S. David, Xavier F. Amador. Insight and Psychosis. second. Oxford University Press; 1998.

2. Lincoln TM, Lullmann E, Rief W. Correlates and Long-Term Consequences of Poor Insight in Patients With Schizophrenia. A Systematic Review. Schizophrenia Bulletin. 2006;33(6):1324-1342. doi:10.1093/schbul/sbm002

3. Kim C-H, Jayathilake $\mathbf{K}$, Meltzer HY. Hopelessness, neurocognitive function, and insight in schizophrenia: relationship to suicidal behavior. Schizophrenia Research. 2003;60(1):71-80. doi:10.1016/S0920-9964(02)00310-9

4. Mintz AR, Dobson KS, Romney DM. Insight in schizophrenia: a meta-analysis. Schizophrenia Research. 2003;61(1):75-88. doi:10.1016/S09209964(02)00316-X

5. Tariku M, Demilew D, Fanta T, Mekonnen M, Abebaw Angaw D. Insight and Associated Factors among Patients with Schizophrenia in Mental Specialized Hospital, Ethiopia, 2018. Psychiatry J. 2019;2019:2453862. doi:10.1155/2019/2453862

6. van der Meer $L$, de Vos AE, Stiekema APM, et al. Insight in Schizophrenia: Involvement of SelfReflection Networks? Schizophrenia Bulletin. 2013;39(6):1288-1295. doi:10.1093/schbul/sbs122

7. Michel $P$, Baumstarck $K$, Auquier $P$, et al. Psychometric properties of the abbreviated version of the Scale to Assess Unawareness in Mental Disorder in schizophrenia. BMC Psychiatry. 2013;13(1):229. doi:10.1186/1471-244X-13-229

\title{
NGHIÊN CỨU MỐI LIÊN QUAN GIỮA ĐĂC ĐIỂM HÌNH THỂ LỖ HOÀNG ĐIỂM CHẤN THƯƠ'NG VỚI KẾT QUẢ PHẪU THUÂTT ĐIỀU TRI
}

\author{
Nguyễn Minh Thi ${ }^{1}$, Thẩm Trương Khánh Vân ${ }^{2}$, Nguyễn Thái Đạt ${ }^{2}$
}

\section{TÓM TẮT}

Lỗ hoàng điểm sau chẫn thương đụng dập nhãn cầu là môt bệnh lý nặng gây tổn hại thị giác trầm trong. Phẩu thuât cắt dich kính, bóc màng ngăn trong và bơm khí nở nội nhã̃n mang laai kết quả khả quan làm đóng lố hoàng điểm và cải thiên thi lực. Mục tiêu nghiên cứu nhằm đánh giá một số yếu tố liên quan đến kết quả điều trị. Chúng tôi tiến hành phẫu thuật cho 61 mắt lỗ hoàng điểm do chấn thương. Kết quả có $57,4 \%$ các mắt có thi lực tăng từ 2 dòng trở lên, lỗ hoàng điểm đóng trong $80,3 \%$ các mắt ở thời điểm 12 tháng sau mổ. Nang bờ lố hoàng điểm liên quan đến mức cải thiện thị lực sau mổ tốt hơn. Những lố

${ }^{1}$ Trường Đại hoc Y Hà nội

${ }^{2}$ Bênh viện Mắt Trung ương

Chịu trách nhiệm chính: Nguyễn Minh Thi

Email: Nguyenminhthi.vnio@gmail.com

Ngày nhận bài: 12.7.2021

Ngày phản biên khoa hoc: 6.9.2021

Ngày duyệt bài: 14.9.2021 hoàng điểm không có dịch dưới bờ lỗ cho khả năng đóng lỗ hoàng điểm tốt hơn. Kích thước đỉnh lỗ hoàng điểm nhỏ có liên quan đến khả năng đóng lỗ hoàng điểm týp 1. nhãn cầu

Tư khóa: Lỗ hoàng điểm, chấn thương đụng dập

\section{SUMMARY}

\section{RESEARCH ON THE RELATIONSHIP BETWEEN} THE CHARACTERISTICS OF TRAUMATIC MACULAR HOLE AND SURGICAL RESULTS

Traumatic macular hole is a serious disease that causes visual damage. Vitrectomy, internal limiting membrane peeling and intraocular air tamponade have good results in hole closure and visual acuity improvement. The purpose of the study is to evaluate factors related to treatment outcomes. We performed surgery for 61 eyes with traumatic macular hole. As a result, $57.4 \%$ of eyes have visual acuity increased by 2 lines or more, macular hole closed in $80.3 \%$ of eyes at 12 months after surgery. Macular hole cysts are associated with better postoperative visual acuity. 